\title{
Referenciamento ou solidão: o coletivo profissional como operador de saúde, desenvolvimento e adoecimento na atividade de trabalho
}

\author{
Letícia Raboud M. de Andrade* \\ Jorge Tarcísio da Rocha Falcão**
}

\begin{abstract}
Resumo
Este trabalho ampara-se nos resultados de uma pesquisa que deu suporte à posterior elaboração de dissertação de mestrado cujo foco voltou-se à atividade de professores pedagogos dos anos iniciais do ensino fundamental da rede municipal de Natal/RN. O artigo fundamenta-se no referencial teórico da clínica da atividade e resgata alguns resultados, enfocando e aprofundando-se na discussão sobre a relevância do coletivo profissional como operador de saúde/desenvolvimento e sofrimento/adoecimento quando da ausência/fragilidade de referenciamento pelo coletivo, o que pode estar relacionado à percepção de solidão laboral.

Palavras-chave: Clínica da atividade; Trabalho docente; Coletivo profissional; Saúde; Solidão.
\end{abstract}

\section{Appartenance ou solitude: le collectif professionnel en tant qu'opérateur de santé, développement et mal-} être dans l'activité de travail

\section{Resumé}

Cet ouvrage s'appuie sur les résultats d'une recherche qui a donné support à l'élaboration postérieure d'un travail de master orienté vers l'activité des enseignants de l'école élémentaire de la ville de Natal/RN. L'article a comme support théorique la perspective de la clinique de l'activité. Il fait référence à quelques résultats, se centrant et s'approfondissant sur la discussion concernant l'importance du collectif professionnel en tant qu'opérateur de santé/développement et souffrance/maladie en cas d'absence/fragilité de référence par le collectif, ce qui peut avoir relation à la perception de solitude au travail.

Mots-clés: Clinique de l'activité; Métier d'enseignant; Collectif professionel; Santé; Solitude.

\section{Introdução}

O presente artigo traz contribuição teórica acerca da importância do coletivo profissional enquanto operador de saúde, desenvolvimento, sofrimento ou adoecimento para os trabalhadores por ele referenciados ou em contexto de ausência desse referenciamento. O trabalho é abordado aqui a partir do referencial teórico da clínica da atividade e apoia-se em resultados oriundos de pesquisa voltada para a atividade de professores pedagogos dos anos iniciais do ensino fundamental da rede municipal de Natal/RN, no intuito de ilustrar relações que envolvem o coletivo de trabalho ou sua ausência e o processo de saúde/desenvolvimento e solidão/adoecimento em contexto laboral. Tal pesquisa deu suporte à dissertação de mestrado e abrangeu etapas quantitativa e clínico-qualitativa que ensejaram análises específicas em processo de publicação. O presente trabalho resgata e reúne resultados e discussões tratados nas duas etapas da pesquisa enfocando e aprofundando a discussão teórica acerca dos vínculos entre coletivo de trabalho, saúde, solidão laboral, empobrecimento da atividade de trabalho e adoecimento do trabalhador.

\section{A clínica da atividade e o coletivo como operador de saúde}

A clínica da atividade enquadra-se no campo das clínicas do trabalho e tem como principal expoente o psicólogo francês Yves Clot. É uma abordagem teórico-metodológica que se fundamenta na ergonomia e psicopatologia de origem francesa, nos estudos do italiano Ivar Odonne, nos trabalhos em filosofia da linguagem do Círculo Bakhtin e na perspectiva histórico-cultural de Vigotski. Nos parágrafos seguintes serão desenvolvidos alguns dos operadores teóricos centrais desta perspectiva.

Clot incorpora à atividade, operador teórico que remonta a Alexis Leontiev e a Marx, a sua dimensão subjetiva, compreendendo-a para além do prescrito (o que deve ser feito) e do efetivamente realizado. $\mathrm{O}$ real da atividade abarca as vivências subjetivas que atravessam tal atividade, e os conflitos com o real, incluindo além do que é feito,

\footnotetext{
*Endereço eletrônico: lelermandrade@ gmail.com

*** Endereço eletrônico: falcao.jorge@ gmail.com
} 
o que se desejaria fazer, o que foi feito a contragosto, o que se deixou para depois, o que precisa ser refeito e ainda o que se faz para não fazer aquilo que deveria ser feito (CLOT et al., 2000; CLOT, 2001, 2008). Clot (1999) refere-se a Vigotski quando entende que "o homem está a cada minuto pleno de possibilidades não realizadas" (p. 119 tradução nossa), enfoque que evidencia as escolhas e os bastidores por trás da atividade: a subjetividade, os conflitos envolvidos, as potencialidades e os limites.

Clot (1999) compreende a atividade de trabalho em contexto de situação real, direcionandose a três polos da ação: o outro, o objeto e si próprio. $\mathrm{O}$ direcionamento ao outro se refere à dimensão interpessoal da atividade, ao fato de que toda a atividade laboral dirige-se a outro além de si mesmo, perdendo o sentido se assim não o for (CLOT, 1999, 2013). O direcionamento ao objeto diz respeito ao prescrito, à dimensão impessoal da atividade, às tarefas instituídas. Trata-se do que dá sustentação ao ofício para além das situações particulares, orientando-o e sendo igualmente capaz de se transformar e enriquecer por meio do trabalho e desenvolvimento diante de diferentes situações (CLOT, 1999, 2013). Por fim, o direcionamento a si próprio refere-se à dimensão pessoal da atividade, a atividade sobre e por si mobilizada e sua expressão singular.

Intermediando as direções explicitadas encontra-se a dimensão transpessoal da atividade, que se refere à história coletiva de um grupo profissional. Esta dimensão que medeia a relação com a atividade diz respeito ao conceito de gênero profissional, que implica em uma memória coletiva de saberes e gestos pertencentes a um coletivo de trabalho e que marca o pertencimento a um grupo, orientando a ação (CLOT et al., 2000; CLOT, 2008). O gênero profissional envolve o recurso dos trabalhadores a uma construção compartilhada da qual podem lançar mão diante das situações que definem a atividade. Trata-se de uma entidade dinâmica, capaz de se desenvolver por meio das variações nas suas formas de utilização diante das situações experienciadas por sujeitos e coletivos de trabalho, sempre aberta e nunca completamente acabada.

Ligado ao conceito de gênero profissional está o conceito de estilo pessoal da atividade, compreendido enquanto uma reformulação do gênero em situação, um trabalho de ajustamento do gênero para torná-lo instrumento da ação com marca pessoal e singular (CLOT et al., 2000;
CLOT, 1999). O estilo pessoal implica em um movimento que inova e desenvolve a relação do trabalhador com o gênero profissional no sentido da eficácia do seu trabalho - a vivência pessoal do trabalho bem-feito (CLOT et al., 2000).

Em relação à compreensão de saúde e doença no contexto da clínica da atividade, o sofrimento é concebido no bojo da atividade contrariada, desenvolvimento impedido (CLOT, 2001). Trabalhadores que não dispõem de recursos para fazer frente aos impasses do real, ou meios para o desenvolvimento destes recursos, encontramse em uma situação de impedimento da atividade. Tal abordagem é claramente tributária da perspectiva de Canguilhem (2009) no sentido de que a saúde não é compreendida como ausência de doença, mas enquanto capacidade de estabelecer novas normas de vida diante das adversidades e dos conflitos que elas ensejam, produzindo desenvolvimento. Deste ponto de vista, situações de entrave e enrijecimento são consideradas problemáticas e potencialmente adoecedoras.

Clot (2008) menciona haver dois caminhos quando o indivíduo é confrontado a atividades desafiantes: a defesa e a resposta de sobrecompensação. A defesa envolve iniciativa de proteção e restrição da atividade, e a resposta de sobrecompensação implica na mobilização de forças que levam a uma efetiva ampliação do poder de agir diante das situações. Destaca-se, no contexto desse segundo caminho, o papel do coletivo de trabalho enquanto força potencialmente mobilizadora de poder de agir diante de situações desafiantes. O poder de agir diz respeito à capacidade de superar contradições, limitações e bloqueios engendrados pelo real da atividade (CLOT, 2008). Nesse sentido, sobre os desafios do trabalho Clot (2008, p.98, tradução nossa) observa que “(...) a resposta possível supõe sempre a elaboração do perigo vivido no seio do coletivo que pode, então, lhe dar um sentido dentro de uma história." Clot salienta ainda o papel dos coletivos de trabalho, por exemplo, na atribuição de sentido às situações vividas, o que está relacionado ao caráter dinâmico de reelaboração coletiva do gênero profissional em face de situações reais, capaz de produzir desenvolvimento no seio do grupo e escapar à rigidez.

A consideração do poder de agir ou sua ausência na perspectiva da promoção do desenvolvimento, saúde e adoecimento, está ligada, conforme mencionado, à inserção do trabalhador em um coletivo de trabalho. Este coletivo pode 
Referenciamento ou solidão: o coletivo profissional como operador de saúde, desenvolvimento e adoecimento na atividade de trabalho

representar o mero agrupamento de co-participantes de uma atividade, mas pode vir a cumprir função crucial enquanto suporte para o desenvolvimento de cada participante e do gênero profissional, na medida em que envolve "um coletivo organizado, historicizado e organizado como gênero profissional (...)." (BENDASSOLLI; DA ROCHA FALCÃO, 2013, p. 1160). Clot (2002, p.04) alude ainda ao fato de que "A saúde se degrada no ambiente de trabalho sempre que um coletivo profissional torna-se uma coleção de indivíduos expostos ao isolamento", quando a história do gênero profissional encontra-se suspensa, cristalizada, e quando "Cada um individualmente se encontra então confrontado às más surpresas de uma organização do trabalho que deixa "sem voz" face ao real.". A saúde é compreendida nessa dinâmica e pauta-se pela percepção de trabalho bem feito, referenciado por uma tradição profissional viva como norte para o "bem estar" de cada indivíduo participante. A dinâmica de co-construção do coletivo e do individual é crucial aqui para o resultado final conducente ao trabalho bem-feito, ou ao trabalho esvaziado, impedido e adoecedor (CLOT, 2013). A discussão sobre os referenciais para a construção de um trabalho bem feito é fundamental para a saúde no trabalho e a impossibilidade de discutir sobre isto gera um sentimento de insignificância nos sujeitos (BENDASSOLLI; DA ROCHA FALCÃO, 2013). A proposta da clínica da atividade vai justamente ao encontro do resgate dessa possibilidade de refletir sobre a própria atividade de trabalho, a partir da análise desta atividade, mas em contexto de recuo analítico possibilitado pelo método e técnicas adotadas (CLOT et al., 2000).

A abordagem teórica acima mencionada é igualmente tributária da perspectiva Vigotskiana que compreende o coletivo como construção dos indivíduos. Discussões e embates dos quais cada indivíduo participa convertem-se em diálogo interior, tecendo pensamento e atividade (CLOT, 2013). Vigotski faz menção à "lei genética geral do desenvolvimento cultural", que concebe que cada função do desenvolvimento cultural existe inicialmente enquanto relação social, e não simplesmente nas relações sociais, como equivocadamente costuma-se compreender (VERESOV, 2004, 2010, 2014). As relações sociais tornam-se funções mentais por meio de uma experiência de "drama", que assume o significado de colisão dramática, pessoal e emocionalmente vivenciada, experimentada primeiro interpsicologicamente enquanto relação social e então intrapsicologicamente, experiência que carrega o potencial para a produção de desenvolvimento (VERESOV, 2014). O coletivo é, então, percebido enquanto recurso para o desenvolvimento das subjetividades individuais, proporcionando o desenvolvimento do pensamento por meio de confrontações, colisões dramáticas sobre as quais se investe e se trabalha coletiva e individualmente (CLOT, 1999, 2013).

\section{Trabalho precarizado, alienação e solidão}

No contexto do capitalismo, em que as relações de produção se fundamentam na exploração de uma parte da população, que precisa vender sua força de trabalho, por outra, que detém os meios de produção, o trabalho é compartimentalizado de modo que não é necessário saber para fazer, ou planejar previamente uma atividade. Trabalho manual e intelectual, planejamento e produção, tornam-se momentos distintos e o trabalhador é destituído de seu saber (ASBAHR, 2005). Na prática pedagógica, em que o produto $\mathrm{e} \mathrm{o}$ ato de produção não podem ser separados, o controle do capital sobre o trabalho ocorre de forma política e ideológica (ASBAHR, 2005). Vasconcellos (1999) refere-se à alienação docente enquanto falta de compreensão e domínio nos vários aspectos da tarefa educativa, apontando para três dimensões: uma dimensão sociológica, em relação à falta de clareza sobre a realidade em que se vive e como as coisas chegaram ao ponto em que estão; uma dimensão política e filosófica, no sentido da falta de clareza em relação à finalidade do que se faz, o homem e a sociedade que se deseja formar; e uma dimensão pedagógica, relativa à falta de clareza quanto à ação mais específica em sala de aula.

Estas manifestações da alienação expressam o impacto subjetivo das condições objetivas em que o sujeito e sua relação com a atividade se constituem, envolvendo um contexto de trabalho precarizado. O tema da precarização do trabalho docente na educação pública básica, no Brasil, é bastante explorado, destacando a situação de baixo investimento a nível financeiro e gerencial por parte do Estado, a intensificação do trabalho do professor pelo aumento do número de alunos em sala de aula e pelo aumento de atribuições das escolas, que 
devem lidar com situações desafiantes envolvendo um cenário social complexo, a incorporação de uma lógica de produtividade, as duplas jornadas de trabalho, os salários insatisfatórios, o comprometimento do tempo disponível para estudo e planejamento, além dos desafios inerentes à profissão (OLIVEIRA, 2004; PAPARELLI, 2009).

A falta de recursos para lidar com uma realidade complexa ou de meios para desenvolver estes recursos, o estabelecimento do trabalho em uma lógica de produtividade e o levantamento de estratégias defensivas diante das dificuldades implicadas na situação de precarização do trabalho relacionam-na ao conceito de trabalho sujo conforme sugerido por Bendassolli e Da Rocha Falcão (2013). Estes autores chamam inicialmente a atenção para o conceito de trabalho sujo como proposto por Hughes (1951), que o identifica a ocupações percebidas como degradantes no plano físico, moral ou ideal, remetendo à ideia de estigma e referindo-se a um fenômeno que pode produzir sofrimento, exclusão e marginalização. A reformulação do conceito proposta por Bendassolli e Da Rocha Falcão (2013) tendo em vista a contribuição das clínicas do trabalho, mais particularmente da clínica da atividade, sugerem o entendimento de trabalho sujo em sua relação com a situação de esquecimento e com a perda de contato com contextos de suporte sociocultural e de mediação, de privação de contato com os coletivos de trabalho, dificultando a relação dos sujeitos com o real. A situação de ter de lidar com o real em um ambiente com poucas referências produzidas/discutidas no contexto de um coletivo de trabalho e/ou gênero profissional envolve um risco de solidão laboral que não se limita às ocupações consideradas de alguma forma degradantes ou sujas, mas pode aplicar-se a qualquer atividade de trabalho (BENDASSOLLI; DA ROCHA FALCÃO, 2013).

No tocante às relações entre trabalho $\mathrm{e}$ saúde, que envolvem situações de precarização, solidão e dificuldades de responder a um real da atividade desafiante, Esteve cunhou em 1999 o termo "mal-estar docente" trazendo contribuições pelo destaque dado às condições sociais envolvidas na atividade laboral dos professores, compreendendo os docentes na organização e em seu entorno social, e não apenas na sala de aula (SOUZA; LEITE, 2011). O mal-estar docente foi definido por Esteve como desencadeado pela desvalorização simultânea às frequentes exigências profissionais, violência, indisciplina, etc., podendo produzir questionamento sobre o sentido da profissão e crise de identidade quanto à escolha profissional (SOUZA; LEITE, 2011). Outra perspectiva de investigação no sentido da relação saúde-trabalho bastante versada no contexto do trabalho docente é o da síndrome de "burnout", que designa sofrimento por exaustão emocional e física em função da exposição seguida a situações de estresse no contexto de trabalho (BATISTA et al., 2010; CARLOTTO, 2002). O burnout ocorre com maior frequência em ocupações que envolvem relações interpessoais intensas, disparidade entre expectativas e realidade, e maior investimento em relação ao cuidado e dedicação ao trabalho, características da profissão docente que é também uma das categorias mais estudadas e suscetíveis ao burnout (SOUZA; LEITE, 2011; CARLOTTO, 2002).

\section{Dos caminhos explorados}

Em contexto de pesquisa que originou dissertação de mestrado foram investigadas as condições e percepções que envolvem a atividade docente do professor pedagogo dos primeiros anos do ensino-fundamental da rede pública municipal de Natal/RN e suas relações com a vivência da atividade de trabalho (ANDRADE, 2017). Para tanto foram estabelecidas duas etapas de pesquisa, a primeira quantitativa e a segunda clínico-qualitativa.

A etapa quantitativa envolveu o uso de um questionário sócio-profissional, abrangendo questões avaliativas relativas aos espaços de discussão e construção coletiva na escola, como a satisfação com as reuniões de planejamento pedagógico semanais, a percepção da presença de discussão teórica nestas reuniões e a familiaridade com o projeto político pedagógico da escola, instrumento que reflete a proposta educacional dos estabelecimentos de ensino, questões para serem respondidas através de uma escala de quatro pontos tipo Likert. Também foi utilizado o instrumento Job Content Questionnaire (JCQ) em versão resumida aplicado no levantamento Sumer 2003 - França (DARES-DRESS, 2008), que avalia as dimensões psicossociais da atividade de trabalho na busca por perfis laborais incluindo o perfil de risco psicossocial. Ao JCQ acrescentou-se uma questão relativa ao sentimento de solidão no trabalho que os professores deveriam igualmente responder por meio de escala de quatro pontos tipo Likert.

O JCQ, também chamado de modelo demanda-controle, avalia três dimensões do ambiente psicossocial de trabalho: a latitude de 
Referenciamento ou solidão: o coletivo profissional como operador de saúde, desenvolvimento e adoecimento na atividade de trabalho

decisão da atividade, referente à percepção de controle sobre a própria atividade e possibilidades de desenvolvimento; A demanda psicológica, relativa à exigência da atividade quanto à rapidez, complexidade e perturbações; E o suporte social recebido de colegas e superiores. Um trabalho com alta demanda psicológica e baixa latitude de decisão constitui um perfil de risco psicossocial, o suporte social podendo atenuar ou potencializar este quadro. Inversamente, um trabalho com baixa demanda psicológica e alta latitude de decisão configura um perfil de baixo risco psicossocial. Um trabalho com alta demanda psicológica e alta latitude de decisão é considerado um trabalho ativo, enquanto um perfil de baixa demanda psicológica e baixa latitude de decisão é tido como perfil de trabalho passivo.

A segunda etapa da pesquisa, de natureza clínico-qualitativa, fez uso da entrevista de instrução ao sósia que compõe o ferramental metodológico da clínica da atividade. A abordagem visa à transformação e ao desenvolvimento no trabalho tendo em vista a ampliação do poder de agir de sujeitos e coletivos por meio de ferramentas que promovem a reflexão e o diálogo sobre/com a atividade.

A clínica da atividade, no quadro da dissertação produzida, foi pensada como modo de aproximação da vivência da atividade dos sujeitos, sendo a vivência, tradução aproximada, em português, para o termo russo "perezhivanie", um conceito vigotskiano referente à experiência dramática no sentido de afetiva e cognitivamente mobilizadora e transformadora, capaz de produzir desenvolvimento (VERESOV, 2004, 2010, 2014). Há também a compreensão metafórica da vivência como um prisma que refrata a experiência (assim como um prisma propriamente dito refrata a luz que sobre ele incide), envolvendo a forma como os indivíduos vivenciam situações a partir do lugar que ocupam e das relações que estabelecem dentro de um contexto social/cultural, sem implicar necessariamente na produção de desenvolvimento (VERESOV, 2014).

A clínica da atividade aproxima-se de ambas as compreensões do conceito de vivência. Em sua perspectiva de ferramenta clínica de intervenção, tendo em vista produzir mobilização e desenvolvimento da atividade no sentido da ampliação do poder de agir, há aproximação com a perezhevanie dramática. Enquanto ferramenta de pesquisa, passível de revelar aspectos das dimensões e do real da atividade, a perspectiva pode dar indícios do prisma que refrata a experiência, assim como das relações estabelecidas com os lugares ocupados pelos sujeitos e coletivos.

A técnica de instrução ao sósia envolve propor ao trabalhador a situação fictícia seguinte: "Suponha que eu serei seu sósia e que amanhã vou substituí-lo em seu local de trabalho. Quais instruções você deveria me transmitir para que ninguém percebesse a substituição?". Através deste questionamento e da busca do pesquisador (sósia) em descobrir os detalhes da atividade, evidenciando aspectos implícitos da mesma, o trabalhador projeta sua atividade no futuro e no sósia, entrando em posição dialógica com um "eu" social, como traz Clot (1999) ao referir-se à Vigotski quando fala sobre promover "um contato social consigo mesmo", permitindo um novo olhar sobre a própria atividade e revelando caminhos de pensamento, escolhas e posicionamentos na confrontação às situações laborais.

O presente artigo se ocupará de comentar alguns resultados da pesquisa empreendida no contexto da dissertação mencionada enfocando os temas de interesse: a solidão no trabalho e o papel do coletivo na produção de saúde e desenvolvimento da atividade. $\mathrm{O}$ artigo não busca evidenciar detalhes do método empregado na pesquisa, fazendo apenas um delineamento geral e centrando-se em aspectos dos resultados que alimentam a discussão que se deseja empreender.

Para a constituição da amostra de professores na primeira etapa da investigação foi utilizado cálculo amostral (SANTOS, 2016) tendo em vista a população de professores do ensino fundamental do município de Natal (1883 professores) de acordo com dados do IBGE para o ano de 2012, estabelecendo efetivo mínimo necessário de 129 participantes. No tocante às escolas públicas municipais estabeleceram-se três grupos de IDEB (Índice de Desenvolvimento da Educação Básica) tendo em vista a distribuição dos valores em uma curva normal, cada grupo representando aproximadamente $1 / 3$ do total das instituições avaliadas, tendo havido sorteio dentro de cada grupo das escolas em que se faria coleta. Apesar das críticas ao sistema de avaliação da educação pública, que não são o foco do presente artigo, o IDEB foi considerado por representar o atual critério de referência na avaliação da "qualidade" das escolas. 
A partir dos resultados encontrados na etapa quantitativa da pesquisa, foram selecionadas duas professoras do $1^{\circ}$ ano do ensino fundamental, pertencentes a escolas diferentes, para a realização da técnica de instrução ao sósia. Realizaram-se dois encontros com cada professora individualmente. Um primeiro encontro de instrução em que as docentes escolheram uma situação mais desafiante ou significativa de sua atividade de trabalho para instrução, momento este gravado e transcrito para posterior análise e apreciação das professoras. E um segundo encontro de confrontação com o relato das docentes sobre a própria atividade tendo em vista proporcionar outra oportunidade de elaboração e reflexão sobre a ação, etapa igualmente gravada e transcrita para análise.

Devido a limitações de tempo e disponibilidade de horários compatíveis entre as docentes, a instrução ao sósia foi realizada individualmente e não coletivamente como originalmente proposto pela abordagem da clínica da atividade, limitando seu potencial de enriquecimento e mobilização no sentido da construção e confrontação com diferentes modos de fazer. No entanto, ainda houve possibilidade de confrontação do trabalhador com a própria atividade, favorecendo a ampliação da consciência sobre a mesma e percepção do campo de possíveis, permitindo igualmente a análise da vivência da atividade e seus atravessamentos que dizem do sujeito e de seu contexto.

Apesar do desenvolvimento da etapa clínico-qualitativa não ter abrangido o coletivo de trabalho, a dimensão coletiva da atividade revelouse fortemente nos relatos das professoras, inclusive pelos impactos de sua ausência.

\section{Solidão no trabalho, manifestações do coletivo e sua relação com a saúde}

Ambas as etapas da pesquisa forneceram indicações das manifestações do coletivo de trabalho e do gênero profissional na atividade laboral e de sua relação com a solidão e a saúde. Estas indicações serão discutidas na presente seção.

$\mathrm{Na}$ primeira etapa de investigação, 30,2\% dos professores analisados revelaram sentirem-se solitários no trabalho. Parcela expressiva que representa pouco mais de $1 / 3$ da amostra estudada. No tocante ao projeto político pedagógico da escola, $47,7 \%$ expressaram possuir pouca familiaridade com o mesmo, também $33,7 \%$ disseram-se insatisfeitos em relação às reuniões de planejamento pedagógico e $40,7 \%$ consideraram pouco expressiva a presença de discussão teórica nas reuniões de planejamento, parcelas superiores a $1 / 3$ da amostra. As três últimas variáveis constituem espaços e instrumentos de discussão e reflexão coletiva, favorecendo a construção de referenciais para a ação, representando oportunidades de enriquecimento e dinamização do gênero profissional. As reuniões de planejamento favorecem o encontro periódico entre profissionais em torno da atividade desenvolvida em sala de aula; a ponte teoria-prática é capaz de produzir reflexões críticas e enriquecer a percepção de fenômenos e repertórios de trabalho cuja separação no contexto da escola, conforme trazido por Haddad e Silva (2012), leva à alienação do trabalho docente; e o projeto político pedagógico é defendido por diversos autores como importante ferramenta de organização da escola e formação continuada de professores com potencial para "produzir transformações na consciência dos educadores num sentido oposto ao da alienação" (ASBAHR, 2005, p.68), envolvendo também a consolidação de um projeto coletivo.

Houve ainda cruzamento das variáveis na busca por relações de dependência e observou-se relação estatisticamente significativa $(\mathrm{p}<0,05)$ entre a variável solidão no trabalho e a satisfação com as reuniões de planejamento, a percepção da presença de discussão teórica nas reuniões de planejamento e a familiaridade com o projeto político pedagógico da escola. Profissionais que se sentem solitários no trabalho tendem a sentirem-se mais insatisfeitos com as reuniões de planejamento, a reconhecerem menor presença de discussão teórica nessas reuniões e a estarem menos familiarizados com projeto político pedagógico da escola do que professores que não se sentem solitários. Estes resultados podem indicar o atravessamento de avaliações positivas ou negativas por parte dos professores, todavia um quadro envolvendo insatisfação com as reuniões de planejamento, percepção de insuficiente presença de discussão teórica nas reuniões e pouca familiaridade com projeto político pedagógico da escola pode implicar em sentimento de solidão no trabalho, haja vista que as variáveis referem-se a condições e ferramentas capazes de produzir referenciais coletivos para a ação, sendo seus entraves ou percepção negativa passíveis de se relacionar a sentimentos de solidão e falta de suporte.

Dos professores pesquisados 19,2\% pertencem a um perfil de risco psicossocial, 30,8\% a 
Referenciamento ou solidão: o coletivo profissional como operador de saúde, desenvolvimento e adoecimento na atividade de trabalho

um perfil de baixo risco psicossocial, $27,3 \%$ são trabalhadores ativos e $22,7 \%$ são trabalhadores passivos. Houve relação de dependência entre o perfil psicossocial, o suporte social e o sentimento de solidão no trabalho. Professores de perfil ativo e em risco psicossocial têm mais chances de sentiremse solitários no trabalho e reconhecerem um baixo suporte social do que profissionais pertencentes aos perfis de trabalho passivo e baixo risco psicossocial. A percepção de maior demanda psicológica características dos perfis de trabalho ativo e em risco psicossocial pode estar associada à percepção de maiores dificuldades na lida com o real da atividade e ausência ou baixo suporte de um coletivo e de referenciais para a ação no enfrentamento de situações desafiantes.

$\mathrm{Na}$ etapa clínico-qualitativa da pesquisa, que será doravante apresentada, foram recrutadas para participar da pesquisa duas professoras do $1^{\circ}$ ano do ensino fundamental da rede municipal de Natal. Uma em situação de risco psicossocial que manifestou sentir-se só no trabalho, chamada na pesquisa de $\mathrm{S}$, e outra com perfil de baixo risco psicossocial que relatou não sentir-se só no trabalho, referida como $\mathrm{M}$, tendo em vista analisar as diferentes vivências e relações estabelecidas com a atividade de trabalho. Alguns dos resultados analisados nas entrevistas de ambas as professoras serão trazidos para discussão.

A professora $\mathrm{S}$, durante momento prévio à instrução, trouxe as dificuldades iniciais com que se deparou enquanto professora, em que teve de dar aulas a uma turma de $5^{\circ}$ ano com 38 alunos em situações heterogêneas de aprendizagem. S relatou prejuízo do seu estado de saúde relacionado ao trabalho, envolvendo calos nas cordas vocais, dor de cabeça e dores no corpo, além de desilusão em relação ao sistema público de educação e críticas às famílias dos alunos.

$\mathrm{S}$ escolheu abordar na instrução o projeto Papai Noel dos Correios nas escolas, em que os alunos devem elaborar uma carta ao Papai Noel e fazer um pedido, recebendo uma resposta e podendo posteriormente ganhar um presente, campanha que visa promover a solidariedade, mas também incentivar a leitura e trabalhar os conhecimentos em relação ao gênero "carta" com as crianças.

Durante a instrução, $S$ enfatiza a falta de motivação de seus alunos. Os trechos seguintes ilustram esta situação e referem-se ao momento de introdução da atividade que precede a escrita do modelo da carta ao Papai Noel pela professora no quadro.

S: Depois de motivadas, quando você perceber que tem a atenção delas, você vai escrever. Enquanto você não perceber a... Que elas estão interessadas naquilo ali, não vai adiantar você ir pro quadro escrever. Então... Tenta, tenta, às vezes você vai achar que estão, mas elas estão só te enganando, é só pra você não brigar mais com elas pra elas pararem e tudo o mais. Mas você faz de conta que tá acreditando nelas também.

(...)

S: Você faz de conta que acredita, porque senão você não faz. E você tem que fazer de qualquer jeito. Do contrário não virão de casa com aquilo pronto não. Ainda que você copie, corre o risco de você se decepcionar porque eles não vão trazer aquela cópia pra passar a limpo a carta.

$S$ revela o real da atividade, aquilo que faz mesmo sem acreditar. Fazer de conta passa a ser condição de realização da atividade, uma atividade esvaziada de sentido. A professora também traz em seus relatos uma interpelação contínua para manter a turma sob controle, como mostram os trechos seguintes.

S: Vamos organizar. Você tem que liderar, você tem que mostrar que você é a pessoa que está à frente da turma porque eles não têm condições de se gerenciar, então você tem que estar à frente da turma. Se você não demonstrar liderança e domínio, você jamais educará essas crianças. Nem pra fazer uma, a, um... As vogais. Porque a questão da aprendizagem começa pelo estímulo, mas também, acima de tudo, pela disciplina. Você precisa estar aberto pra receber o que o outro vai te dar e você só se abre se você for convencido.

Neste trecho o uso da palavra "domínio" e "convencido" envolvem uma percepção passiva dos alunos que se contrapõe à compreensão dos mesmos enquanto ativos e coprodutores de seu processo de aprendizagem, além de pender para o uso da autoridade no sentido da ideia de adestramento.

No segmento abaixo, $\mathrm{S}$ aborda os impedimentos de sua atividade e dirige-se ao trabalho docente como uma batalha que deve ser vencida. $\mathrm{O}$ segmento evidencia também o foco na produção dos alunos, elemento recorrente nos relatos de $\mathrm{S}$, que revela uma lógica de desempenho. 
S: Mas você consegue fazer a atividade com mais tempo, então se eles não concluírem você retoma no dia seguinte, e retoma no dia seguinte. E o trabalho do professor é essa constante retomada até que... Que você consiga vencer eles pelo cansaço. E aí você consegue fazer a produção.

Ao longo dos relatos de $\mathrm{S}$ observou-se ainda que, apesar de tratar-se de uma professora do $1^{\circ}$ ano do ensino fundamental, período em que há grande ênfase na alfabetização, a docente fez apenas menções indiretas ao processo, colocando principalmente em foco aspectos de gestão da turma.

Embora $\mathrm{S}$ não fale explicitamente em solidão nos seus relatos, a docente encontra-se, conforme trazido por Clot (2002), sem voz face ao real, e expressa sofrimento e desilusão em relação ao trabalho, bem como indica modos defensivos de funcionamento que focam em estratégias de controle da turma e produção no sentido do desempenho, elementos potencialmente aprisionadores de sua atividade. S também não faz muitas menções a recursos e instrumentos de mediação e enriquecimento da atividade, focando nos entraves da mesma. É possível falar em trabalho sujo no sentido proposto por Bendassolli e Da Rocha Falcão (2013) de perda de contato com contextos de suporte sociocultural, de privação de contato com um coletivo, que embora possa existir, não parece estar cumprindo sua função para $S$, ampliando as dificuldades na lida com o real.

A professora $\mathrm{M}$, em momento anterior à instrução, colocou como elementos centrais da sua atividade a alfabetização e o letramento dos alunos, enfatizando a satisfação que tem com seu trabalho e o fato de ter alfabetizado muitos alunos e favorecido o gosto das crianças pela leitura, avaliação que aponta no sentido da percepção, por $M$, de um trabalho bem feito.

A docente escolheu para instrução o momento após o intervalo, ocasião em que as crianças chegam mais agitadas à sala de aula e é preciso retomar as atividades e se concentrar. Os trechos abaixo ilustram recursos usados por $\mathrm{M}$ para recentrar a atenção dos alunos, como técnicas de relaxamento, além de explicitar o foco da professora no aprender.

M: Essa técnica de relaxamento você pede pra que eles sentem e vamos, a gente vai fazer silêncio e vamos contando, eh... Eu faço os gestos com os dedos. Você deve fazer assim, um, aí dá uma respirada, dois, a segunda respirada, três... Isso pausadamente pra que eles possam respirar naquele ritmo mais calmo, né? E pra ir voltando à calma.

(...)

M: "Vamos fazer um relaxamento, pessoal. Vamos fazer um relaxamento pra gente voltar mais à calma, vocês correram muito, vocês estão cansados, vocês estão ofegantes. Então tá na hora da gente parar um pouquinho, respirar, pra que vocês possam melhorar a respiração e melhorar também a concentração pra gente aprender melhor.". Você diz essas palavras mais ao menos, né, porque o objetivo é esse. Certo? É que eles possam voltar à calma e assim, se concentrar melhor, né?

Ao longo das instruções, $M$ trouxe diferentes mediações e estratégias de trabalho como, por exemplo, as relacionadas à promoção do contato das crianças com os livros, como ter um cantinho da leitura na sala e um momento semanal para utilização deste espaço, além de ferramentas voltadas à fixação da atenção das crianças em elementos das histórias contadas em sala, como o uso de desenhos e o sorteio de perguntas após a leitura de trechos da história.

Além dos diversos instrumentos mobilizados pela docente, chamou a atenção o fato de $\mathrm{M}$ ter passado o ano sem livro didático devido a problemas burocráticos (o município não disponibilizou o material para sua turma). A professora trouxe que o fato de não seguir o livro didático facilitou o trabalho de alfabetização dos alunos, apesar de ter havido um maior esforço na pesquisa das atividades a serem utilizadas. $M$ revelou orientar-se pelos direitos de aprendizagem estabelecidos pelo Pacto Nacional pela Alfabetização na Idade Certa (PNAIC), programa de formação continuada oferecido nos sistemas de ensino, e apontou para o fato de que nem todos os livros seguem a orientação proposta pelo PNAIC.

M: Então esse ano, eh... Ficou um pouquinho mais complicado que a gente não teve livro didático pra ajudar, por outro lado os livros didáticos eles ainda... Alguns ainda não estão nessa orientação do PNAIC. Tá entendendo? Então, pra mim facilitou um la... Uma questão de, de colocar em prática essa, esses direitos de aprendizagem. Mas por outro dificultou porque eu tenho que pesquisar muito, né. Atividades fora do contexto dos livros didáticos, então... Dificultou nesse aspecto, mas por outro eu acho que num, num... Facilitou até a questão da 
Referenciamento ou solidão: o coletivo profissional como operador de saúde, desenvolvimento e adoecimento na atividade de trabalho

alfabetização, porque você não fica preso a um livro. Aquele, "Ah, eu tenho que terminar esse programa do livro todinho aqui." Né? Às vezes atrapalha muito o professor essa questão.

O desafio de não possuir livro didático converteu-se para $M$, embora não sem custos, em uma forma de ampliação de sua autonomia e poder de agir sobre a situação encontrada. No entanto isto só foi possível tendo em vista a construção de referenciais para a ação pela professora, que atribui à experiência e aos cursos do PNAIC o favorecimento da construção destes referenciais.

M: Se você conhece realmente muita, mais coisa, tem mais experiência... Eu acho que a experiência conta muito nessa hora. De você saber julgar, né, o que é que um livro pode ajudar e quando ele atrapalha um pouquinho. Né, no meu caso dificultou a questão da pesquisa (necessidade de pesquisar as atividades), mas por outro lado, como eu faço o PNAIC desde 2013, há três anos que eu faço, né? Bem direitinho, sem faltar aos encontros. Eu fiz o de língua portuguesa, fiz o de matemática, fiz a parte de projetos, né, de, de ter um conteúdo voltado pra questão de projetos, de sequência didática. Então me ajudou muito! Tanto que eu nem senti muita falta do livro didático. Entendeu?

$\mathrm{O}$ trecho seguinte refere-se ao momento de reação de $\mathrm{M}$ à técnica de instrução ao sósia. A professora considera positiva a reflexão sobre a prática e traz que o exercício já era realizado nos encontros do PNAIC.

M: Eh, a oportunidade de refletir sobre a prática é muito bom, né? A gente já faz muito isso nos encontros do PNAIC. De refletir sobre a prática, de ver a prática de outros professores e discutir, né. Faz assim, não faz assim, porque assim não deu certo, porque assim deu certo. A gente já tem essa prática.

O segmento acima revela os encontros do PNAIC como momentos de discussão e troca sobre os diferentes estilos, modos de fazer da atividade, capaz de produzir enriquecimento e mobilização do gênero profissional tendo em vista a construção de referenciais coletivos no sentido do trabalho bem feito.

As falas da professora $M$ revelam dinamismo e estão constantemente atravessadas, mediadas, pelo gênero profissional. Conforme trazido nos parágrafos anteriores, $\mathrm{M}$ refere-se aos cursos e às orientações do PNAIC como elementos de enriquecimento da atividade de trabalho, do gênero profissional, favorecendo a construção de referenciais para a ação, a relação com o real e o desenvolvimento do poder de agir. A construção coletiva e o acesso aos suportes socioculturais tendo como horizonte o trabalho bem feito contribuem para a produção de saúde, desenvolvimento e sentimento de satisfação no trabalho.

\section{Considerações finais}

Os resultados discutidos exemplificam e reforçam a importância dos coletivos de trabalho, bem como dos suportes socioculturais que nutrem o gênero profissional, na construção de referenciais de ação direcionados à realização de um trabalho bem feito tendo em vista a saúde e o desenvolvimento da atividade.

Dos resultados quantitativos ressalta-se o elevado percentil de professores dos anos iniciais do ensino fundamental da rede municipal de Natal/RN que se sentem solitários no trabalho e a associação desta variável à condição de risco psicossocial dos docentes e à percepção negativa de elementos do contexto de trabalho que poderiam ser espaço de construção coletiva e suporte sociocultural à ação, apontando para possíveis entraves destas ferramentas (reuniões de planejamento pedagógico, presença de discussão teórica nas reuniões e familiaridade com o projeto político pedagógico das escolas) e das possibilidades de desenvolvimento da atividade.

Nos resultados clínico-qualitativos os relatos de $\mathrm{S}$ retratam o peso da possível ausência ou entrave no funcionamento do coletivo de trabalho, que dificulta a lida com desafios da prática e propicia a situação de encontrar-se sem voz face ao real, como ocorre com a docente. S expressa sintomas clínicos (dor de cabeça, calo nas cordas vocais, dores no corpo) e desilusão em relação ao trabalho, faz poucas menções a recursos e mediações que possa lançar mão na atividade e enfoca os entraves da ação e estratégias defensivas produzidas (busca de controle dos alunos e produção tendo em vista o desempenho das crianças), o que expõe a sua solidão. Por sua vez, os relatos de $\mathrm{M}$ revelam o social/coletivo na atividade de trabalho, os referenciais construídos pela experiência, orientações e discussões sobre os 
modos de fazer de professores no contexto do PNAIC. A prática de $\mathrm{M}$ é mediada, traz recursos para lidar com os desafios e apresenta-se criativa e dinâmica. A satisfação no trabalho expressa pela docente enfatiza a trilha do trabalho bem feito em uma cultura compartilhada como norte para o bem estar.

$\mathrm{S}$ e $\mathrm{M}$ expressam em sua vivência da atividade diferentes formas de relacionamento com a mesma e não podem ser compreendidas fora de seus contextos históricos e objetivos, especialmente considerando a complexidade do cenário educacional na rede pública. Como aponta Anjos (2013) existem questões estruturais que ultrapassam o poder de ação dos professores e estão ligadas à organização do sistema educacional e à função da escola na sociedade e suas contradições, afetando diretamente o trabalho docente e constituindo-o. Conforme considera Anjos (2013), ainda que o coletivo de professores possa produzir suporte à ação na relação com a realidade, é necessária uma luta em diversas instâncias pela mudança nas condições estruturais que constituem a atividade docente. Nesse sentido, os coletivos podem ser vetores de organização e ampliação da consciência sobre a realidade na contramão da alienação.

\section{Referências}

ANDRADE, L. R. M. O professor polivalente dos anos iniciais do ensino fundamental da rede municipal de Natal/RN: trabalho, vivência e mediações. 2017. 201 f. Dissertação - Programa de Pós-graduação em Psicologia da UFRN, Natal, 2017.

ANJOS, D. D. A profissão docente em questão: Gênero de atividade, gênero do discurso e habitus. 2013. Tese - Faculdade de Educação da Universidade Estadual de Campinas, Campinas, 2013.

ASBAHR, F. S. F. Sentido pessoal e projeto político pedagógico: Análise da atividade pedagógica a partir da psicologia histórico-cultural. 2005. Dissertação. Universidade de São Paulo, São Paulo, 2005.

BATISTA, J. B. V.; CARLOTTO, M. S.; COUTINHO, A. S.; AUGUSTO, L. G. S. Prevalência da Síndrome de Burnout e fatores sociodemográficos e laborais em professores de escolas municipais da cidade de João Pessoa, PB. Rev Bras Epidemiol, v.13, n.3, p. 502-512, 2010.

BENDASSOLLI, P. F.; DA ROCHA FALCÃO, J. Psicologia social do trabalho sujo: revendo conceitos e pensando em possibilidades teóricas para a agenda da psicologia nos contextos de trabalho. Universitas Psychologica, v.12, n.4, p.1153-1166, 2013.

CANGUILHEM, G. O normal e o patológico (M. T. R. C. Barrocas, Trad.). Rio de Janeiro: Forense Universitária, 2009.

CARLOTTO, M. S. A síndrome do burnout e o trabalho docente. Psicologia em estudo, v. 7, n. 1, p. 21-29, 2002.

CLOT, Y. La fonction psychologique du travail. Paris: Presses Universitaires de France, 1999.

CLOT, Y. Clínica do trabalho, clínica do real. Le journal des psychologues, v.18, 2001.

CLOT, Y. Clínica da atividade e repetição. Cliniques Méditerranéennes, v. 66, 2002.

CLOT, Y. Travail et pouvoir d'agir. 1. ed. Paris:

Presses Universitaires de France, 2008

CLOT, Y. O ofício como operador de saúde. Cadernos de Psicologia Social do Trabalho, v. 16, n. 1, p. 1-11, 2013.

CLOT, Y.; FAITA, D.; FERNANDEZ, G. ; SCHELLER, L. Entretients en autoconfrontation croisée: une méthode en clinique de l'activité. Perspectives interdisciplianires sur le travail et la santé, v.2, n.1, p. 1-8, 2000.

DARES-DRESS. Les Facteurs Psychosociaux au Travail : Une évaluation par le questionnaire de Karasek dans l'enquête Sumer 2003. Premières Synthèses, v. 22, p. 1-8, 2008.

ESTEVE, J.M. O mal-estar docente: a sala de aula e a saúde dos professores. Bauru: EDUSC, 1999. 
Referenciamento ou solidão: o coletivo profissional como operador de saúde, desenvolvimento e adoecimento na atividade de trabalho

HADDAD, C. R.; SILVA, D. V. A hora atividade como processo de formação continuada. In: IX ANPED Sul (Orgs.), Seminário de Pesquisa em Educação da Região Sul, 2012.

HUGHES, E. Work and the Self. In: ROHRER, J. H.; SHERIF, M. (Eds.). Social psychology at the crossroads. New York: Harper, 1951, p.313-323.

IBGE - INSTITUTO BRASILEIRO DE GEOGRAFIA E ESTATÍSTICA. Docentes - Ensino fundamental - escola pública municipal. Natal: IBGE, 2012.

OLIVEIRA, D. A. A reestruturação do trabalho docente: precarização e flexibilização. Educ. Soc., v. 25 , n. 89, p. 1127-1144, 2004.

PAPARELLI, R. Desgaste mental do professor da rede pública de ensino: trabalho sem sentido sob a política de regularização de fluxo escolar. 2009. Tese. Universidade de São Paulo, São Paulo, 2009.

SANTOS, G. E. O. Cálculo amostral: calculadora on-line.

Disponível
$<$ http://www.calculoamostral.vai.la>. Acesso em: $10 / 04 / 2016$

SOUZA, A. N.; LEITE, M. P. (Coord.). Condições de trabalho e suas repercussões na saúde de professores da educação básica no Brasil. Educ. Soc., v. 32, n.117, p. 1105-1121, 2011.

VASCONCELLOS, C. S. Planejamento: Projeto de ensino-aprendizagem e projeto político pedagógico. São Paulo: Libertad, 1999.

VERESOV, N. Zone of proximal development (ZPD): the hidden dimension? In: OSTERN, A.; HEILA-YLIKALLIO, R. (Eds.). Sprak som kultur brytningar I tid och rum (pp.13-30). Vasa: Abo Akademi - Pedagogiska fakulteten, 2004.

VERESOV, N. Forgotten methodology : Vygotsky's case. In: TOOMELA, A.; VALSINER. J. (Eds.). Methodological thinking in psychology: 60 years gone astray? United States: IAP, 2010, p. 267-295.

VERESOV, N. Émotions, perezhivanie et développement culturel : le projet inachevé de Lev Vygostki. In: MORO, C. ; MIRZA, N. M. (Orgs.) Sémiotique, culture et développement psychologique. Villeneuve d'Ascq: Presses Universitaires du Septentrion, 2014, p. 209-235.

\section{Sobre os autores}

Letícia Raboud Mascarenhas de Andrade é psicóloga e mestre em psicologia pela UFRN.

Jorge Tarcísio da Rocha Falcão é psicólogo, mestre e doutor em Psicologia. Fez estágio pós-doutoral no Conservatoire National des Arts et Métiers (CNAM), em Paris (França É professor titular e pesquisador do departamento de psicologia e docente da pós-graduação em psicologia da Universidade Federal do Rio Grande do Norte.

Recebido em outubro de 2017.

Aprovado em novembro de 2017. 